\title{
Congenital Lobar Emphysema in a 17-Day-Old Male Neonate: The Plain Radiographic Features and a Case Report
}

\author{
Sule MB ${ }^{1^{*}}$, Umar AU ${ }^{2}$, Gele $\mathrm{IH}^{3}$, Ribah $\mathrm{MM}^{3}$ and Aliyu $\mathrm{AZ}^{3}$ \\ ${ }^{1}$ Radiology Department, Usmanu Danfodiyo University, Sokoto. \\ ${ }^{2}$ Radiology Department, Gombe State University, Gombe. \\ ${ }^{3}$ Radiology Department, Usmanu Danfodiyo University Teaching Hospital, Sokoto.
}

*Corresponding Author: Sule Muhammad Baba; Department of Radiology, Usmanu Danfodiyo University, Sokoto.

Received date: December 19, 2021; Accepted date: January 05, 2022; Published date: January 12, 2022

Citation: Sule MB, Umar AU, Gele IH, Ribah MM and Aliyu AZ. (2022). Congenital Lobar Emphysema in a 17-Day-Old Male Neonate: The Plain Radiographic Features and a Case Report. J Thoracic Disease and Cardiothoracic Surgery, 3(1); DOI: 10.31579/2693-2156/037

Copyright: (C) 2022, Sule Muhammad Baba, This is an open access article distributed under the Creative Commons Attribution License, which permits unrestricted use, distribution, and reproduction in any medium, provided the original work is properly cited.

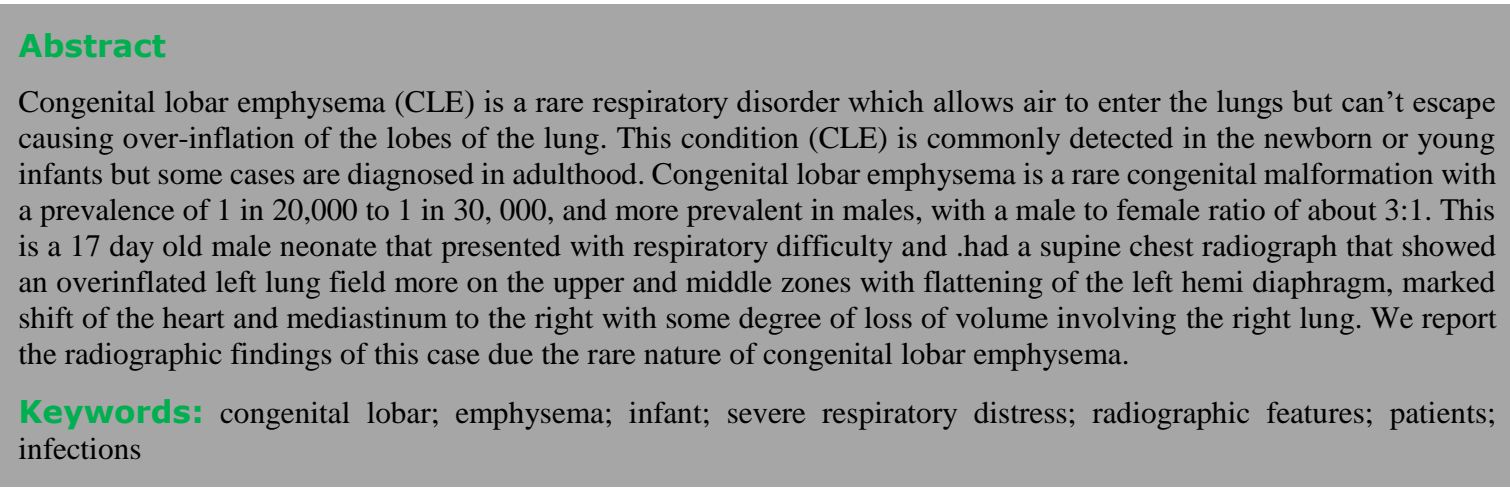

\section{Introduction}

Congenital lobar emphysema is a rare malformation of lung development characterized by over distension of a lobe following partial obstruction of the bronchus [1,2]. Congenital lobar emphysema is also known as congenital alveolar over distension, congenital lobar over-inflation and infantile lobar emphysema [3]. Congenital lobar emphysema is a rare congenital malformation with a prevalence of 1 in 20,000 to 1 in 30,000 $[3,4]$. Congenital lobar emphysema been a rare disease may be the cause of severe respiratory distress in the infant and neonates [1,5]. Congenital lobar emphysema is a reversible and possibly life threatening cause of respiratory distress in the neonatal period, as many as $25 \%$ of the patients, presentation may be delayed until the first month of life [6].

Congenital lobar emphysema has an unknown etiology but thought to occur as an aberration in the normal lung development in the third week of gestation [3, 7-9]. The condition usually presents with varying features from acute respiratory failure to recurrent episodes of tachypnea or infections $[4,9,10]$.

Congenital lobar emphysema is usually unilateral affecting the upper left lobe in about $43 \%$, followed by the middle right lobe in $32 \%$, with bilateral involvement of the lobes of the lung been reported $[9,11,12]$. Congenital lobar emphysema is often associated with congenital heart disease with a $12-20 \%$ concomitant rate, the presence of congenital heart disease especially in infants with respiratory distress symptom should be considered [1,13]. The main management of CLE is by surgical intervention; lobectomy, the removal of the affected lobe of the lung $[3,5,7]$.

\section{Case Report:}

This is a 17 day old male neonate being managed for neonatal sepsis, presented with difficulty in feeding and breathing, wheezing and cyanosis. The patient has features of chronic cough and respiratory infections. The patient was referred for a plain chest radiograph from a peripheral health-care center. He is a full term neonate and given birth by a successful vaginal delivery. The pregnancy and birth was uneventful. No history of similar occurrence in the family, the parents are from a village and merely farmers not gainfully employed. The patient was referred from a peripheral clinic for a chest radiograph on account of respiratory difficulty that was noticed to be persistent since first week of birth. On physical examination, the patient had wheezes and rhonchi, with hyper-resonance following percussion of the left lung field and diminished breath sounds on the left chest following auscultation. The cardiovascular examination was normal. The patient had a supine chest radiograph that showed an overinflated left lung field mainly involving the upper and middle zones with flattening of the left hemi diaphragm, 
marked shift of the heart and mediastinum to the right with some degree of loss of volume involving the right lung. See (figure 1). No feature to suggest congenital heart disease and fractures of the bony thorax were demonstrated on the radiograph.

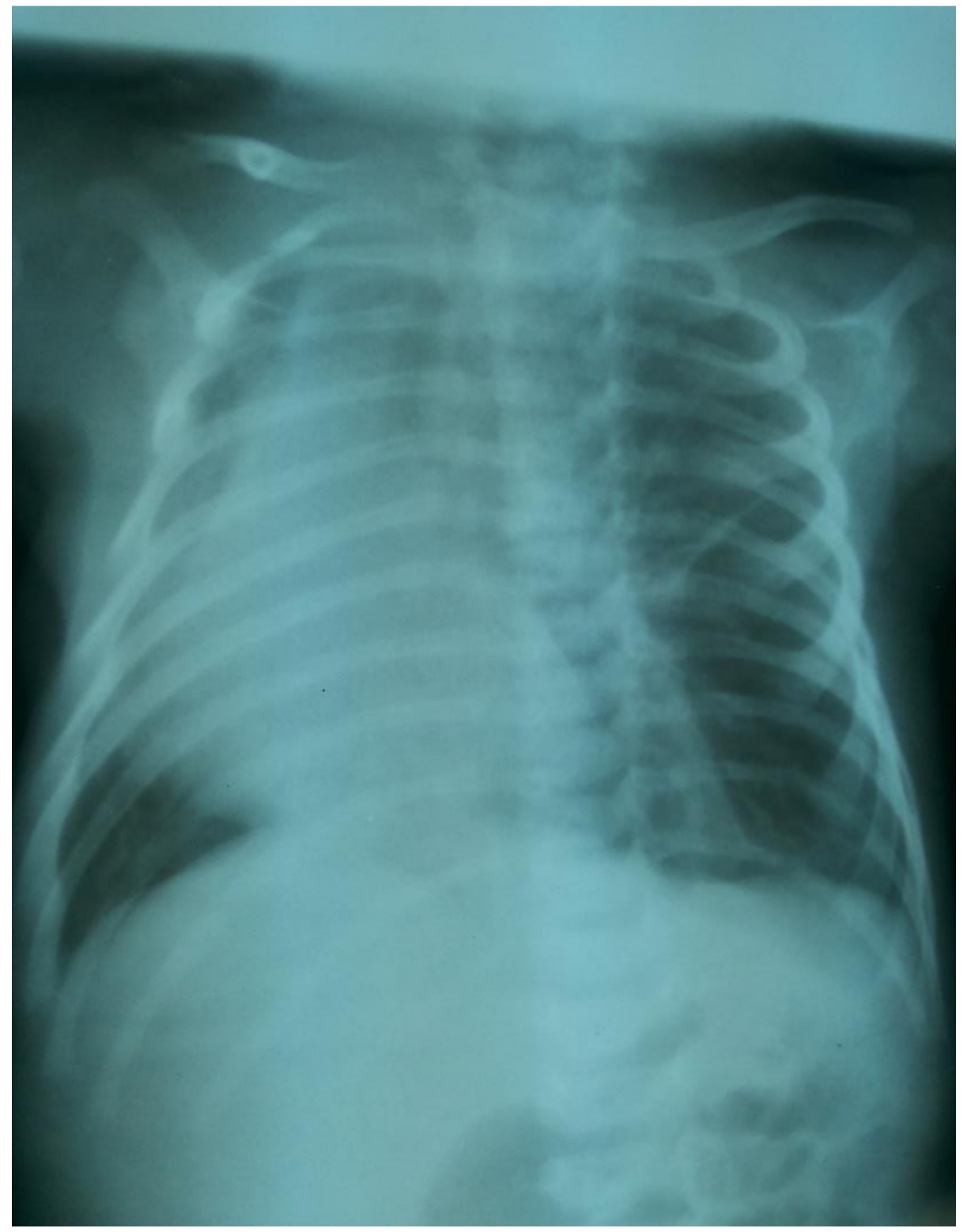

Figure 1: A supine plain radiograph showing an emphysematous left lung field (predominantly the upper and middle zones) with flattened left hemi diaphragm and severe displacement of the heart and mediastinum to the right side. There is loss of volume involving the right lung field.

\section{Discussion}

Congenital lobar emphysema (CLE) as a rare condition has an unknown etiology and commonly present in the neonatal age [5]; our case is a 17 day neonate and we could not determine the possible etiology in the patient. The condition is more prevalent among the males, and commonly seen in neonatal age group as documented in most literatures, the case under presentation is a male neonate, thereby conforming to that documented in most literatures $[5,9,12]$. The patient presented with features of respiratory distress; these features are those documented among patients with CLE in most literatures [5-8]. No history of similar occurrence among the siblings and members of the family to rule out the suspicion of hereditary occurrence as documented in some literatures. The classical involvement of the left lung; upper lobe/zone as documented in most literatures [3-5] was also demonstrated in this case as the left upper zone was mainly affected. The shift of the mediastinum and heart to the contralateral side and associated loss of volume involving the remaining lung lobes were also demonstrated in the index case. Some of the literatures reported the association of CLE with cardiac anomalies like patent ductus arteriosus, atrial septal defect, ventricular septal defect, and tetralogy of Fallot to mention but a few $[5,14,15]$; these associations were not evident in the index case. The treatment of CLE is mainly surgical by lobectomy and in some instances conservatively, depending on the degree of severity of the respiratory distress [5], the patient is currently managed conservatively conforming to that documented in the literature.

\section{Conclusion}

Congenital lobar emphysema is indeed a rare condition and is often life threatening, the review of these cases with baseline radiographic exposure 
will help in making prompt diagnosis and subsequently salvaging the lives of these patients.

\section{References}

1. Asok KD, Syamali M, Jadab KJ. (2009). Congenital lobar emphysema: A case report. Cass Journal.2009; 2:67.

2. Cunha FM, Pinheiro FD, Amaro FD. (2008). Congenital lobar emphysema: Study of a case. Rev Port Pneumol. 2008; 14:893896.

3. Christopher MD. Congenital lobar emphysema.

4. Thakral CL, Maji DC. Sajwani MJ. (2001). Congenital lobar emphysema: experience with 21 cases. Pediatr Surg Int. 2001; 17:88.

5. Omer FD, Melih H, Mehmet K. (2019). Congenital lobar emphysema: diagnosis and treatment options. Int $\mathrm{J}$ Chron Obstruct Pulmon Dis. 2019; 14:921-928.

6. Emphysema, Congenital Lobar. Rare diseases.org. Accessed on $27^{\text {th }}$ November 2019.

7. Pariente G, Aviram M, Landau D, Hershkovitz R. (2009). Prenatal diagnosis of congenital lobar emphysema: case report and review of the literature. J Ultrasound Med. 2009; 28:10811084.

8. Correia-Pinto J, Gonzaga S, Huang Y, Rottier R. (2010). Congenital lung lesions underlying molecular mechanisms. Semin Pediatr Surg. 2010; 19:171-179.
9. Ceran S, Altuntas B, Sunam GS, Bulut I. (2010). Congenital lobar emphysema. Is surgery routinely necessary? Afr J Paediatr Surg. 2010; 7:36-37.

10. Schwartz MZ, Ramachandra P. (1997). Congenital malformations of the lung and mediastinum-a quarter century of experience from a single institution. J Pediatr Surg. 1997; 32:44-47.

11. Miller CG, Woo-Ming MO, Carpenter RA. (1968). Lobar emphysema of infancy. Case report of bilateral involvement with congenital heart disease. West Indian Med J. 1968; 17:3540.

12. May RL, Mese EH, Times JJ. (1964). Congenital lobar emphysema: case report of bilateral involvement. J Thorac Cardiovasc Surg. 1964; 48:850-854.

13. Dogan R, Dogan OF, Yilmaz M, Passaglu I, Kliper N, Ozecelik U, Boke E. (2004). Surgical management of infant with congenital lobar emphysema and concomitant heart disease. Heart Surg Forum. 2004; 6:644-649.

14. Moideen I, Nair SG, Cherian A, Rao SG. (2006). Congenital Lobar emphysema associated with congenital heart disease. J Cardiothoracic Vasc Anesth. 2006; 20:239-241.

15. Elmaci TT, Guler N, Aydogan U, Onursal E. (2001). Infantile lobar emphysema and tracheal bronchus in a patient with congenital heart disease. J pediatr Surg. 2001; 36:1596-1598.

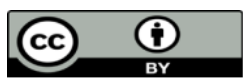

This work is licensed under Creative Commons Attribution 4.0 License

To Submit Your Article Click Here:

Submit Manuscript

DOI: $10.31579 / 2693-2156 / 037$
Ready to submit your research? Choose Auctores and benefit from:

$>$ fast, convenient online submission

$>$ rigorous peer review by experienced research in your field

$>$ rapid publication on acceptance

$>$ authors retain copyrights

$>$ unique DOI for all articles

$>$ immediate, unrestricted online access

At Auctores, research is always in progress.

Learn more https://auctoresonline.org/journals/journal-of-thoracic-disease-andcardiothoracic-surgery 